\title{
A interface rizomática do acervo: construção do dossiê arquivístico para elaboração de edições digitais
}

\author{
The rbizomatic interface of the collection: construction of the archival \\ dossier for the preparation of digital editions
}

Iago Gusmão Santiago*

Universidade Estadual de Feira de Santana

Feira de Santana, Bahia, Brasil

Stephanne da Cruz Santiago**

Universidade Estadual de Feira de Santana

Feira de Santana, Bahia, Brasil

Patrício Nunes Barreiros***

Universidade Estadual de Feira de Santana

Feira de Santana, Bahia, Brasil

Resumo: A filologia, ao longo do tempo, tem adotado diferentes métodos para a edição de textos. A depender do tipo de texto e dos objetivos da edição, a abordagem metodológica pode variar. Atualmente, novas discussões acerca da edição de texto têm levado os filólogos a repensar o seu labor, a partir do questionamento do estatuto do texto, que transcendeu seu aspecto alfanumérico e se inseriu no universo digital. A informática e seus desdobramentos contemporâneos anunciaram uma nova fase da cultura escrita que está exigindo um novo olhar para o texto e seus processos de transmissão. O acervo do escritor baiano Eulálio Motta (1907-1988) abarca uma variedade de documentos pessoais, sua produção literária édita e inédita, correspondências, diários, coleções de objetos etc. Esses documentos funcionam como lugar de memória, possibilitando a reconstrução de uma parcela significativa da vida e da obra do escritor. No acervo, os documentos estão integrados por meio de uma rede de relações com significados importantes. Portanto, ao editar um texto que faz parte do acervo, faz-se necessário esboçar um modelo de edição que garanta a manutenção dessa rede de significados. Barreiros (2013; 2015) propôs um modelo de hiperedição que inclui um dossiê arquivístico, que é uma forma de integrar, por meio de hiperlinks, os paratextos e os protextos do documento editado. Dessa forma, é possível estabelecer uma rede de relações entre o texto editado e os documentos do acervo. O presente artigo apresenta um estudo acerca da construção do dossiê arquivístico elaborado para a edição digital dos textos publicados por Eulálio Motta no jornal Mundo Novo e dos rascunhos de cartas do caderno Farmácia São José. Para exemplificar o estudo, serão utilizado como exemplos os dossiês arquivísticos de dois textos: CARTA ABERTA (28-08-1931) do jornal Mundo Novo e Carta aberta a um amigo do caderno Farmácia São José.

Palavras-chave: Filologia digital. Edição digital. Dossiê arquivístico.

* Graduado em Letras: Português e Espanhol da UEFS, bolsista de iniciação tecnológica CNPq/2016, bolsista de iniciação científica FAPESB/2017 e CNPq/2015: Email: gusmaoiago@gmail.com.

** Graduada em Letras com Língua Inglesa da UEFS, bolsista de iniciação científica CNPq/2016, PROCAD/CNPq/2017 e FAPESB/2015: Email: stephannesantiago@gmail.com.

*** Doutor em Letras e Linguística, professor da Universidade Estadual de Feira de Santana, coordenador do projeto de pesquisa Edição das obras inéditas de Eulálio Motta, financiado pela FAPEB e pelo CNPq. Email: patricio@uefs.br. 


\begin{abstract}
Philology, over the years, has taken different methods for the edition of texts. Depending on the kind of text and the goals of the edition, the methodological approach may change. Nowadays, new discussions about the edition of text has led philologists to rethink their work, by questioning the statute of the text, which has transcended its alphanumeric aspect and now takes part in the digital universe. Computing and its contemporary developments have announced a new phase of writing culture that is demanding a new way of looking to the text and its transmission process. The collection of the bahian writer Eulálio Motta (1907-1988) embraces a variety of personal documents, his literary production that was published and unpublished, mailing, diaries, collection of objects, etc. These documents work as a place of memory, making possible the reconstruction of a great part of the writer's life and work. In the collection, the documents are integrated by a network of relations that has important meanings. However, by editing a text that is part of the collection, it is necessary to sketch a model of editing that ensures the maintains this network of meanings. Barreiros $(2013$; 2015) proposed a model of hyperedition that includes a archivistical dossier, which is a way of integrating, by hyperlinks, the paratexts and prototexts of the edited document. Therefore, it is possible to stablish a network of relations between the edited text and the documents of the collection. The present work presents a study on the construction of the archivistical dossier that was elaborated for the digital edition of the texts that were published by Eulálio Motta on the newspaper Mundo Novo and the sketches of letters of the notebook Farmácia São José. To exemplify the study, will be used as examples the archivistical dossiers of two texts: CARTA ABERTA (28-08-1931) from the newspaper Mundo Novo and Carta aberta a um amigo from the notebook Farmácia São José.
\end{abstract}

Keywords: Digital philology. Digital edition. Archivistical dossier.

\title{
1 INRODUÇÃO
}

Resultado de uma atividade de arquivamento de si feita no decurso de sessenta anos, o acervo do escritor mundonovense Eulálio de Miranda Motta (1907-1988) compreende uma grande diversidade de materiais pertencentes aos mais variados estágios da sua produção escrita, tanto literária como não-literária, além de documentos e objetos pessoais. Esse acervo não é um conjunto assistêmico de guardados, ele se constitui como um produto autobiográfico, uma escrita de si, resultante de um processo de contínuas reescritas. Entende-se que essa construção não seja um ato inocente e despretensioso do escritor que, notadamente, ao organizar o acervo, tinha em vista um provável leitor. Todavia, tal argumento não desautoriza a legitimidade da documentação, mas salienta a complexidade que reside em debruçar-se sobre ela como objeto de estudo.

É certo que a documentação do acervo preserva as memórias do escritor, mas desvendar cada uma das histórias dos documentos é um desafio que se impõe aos pesquisadores que estudam o acervo. Nesse contexto, os objetos figuram não como detentores de uma história pronta para ser lida, mas sim como indícios dela, servindo para fundamentar a construção de narrativas, já que, conforme afirma Barreiros (2013; 2015), a linguagem é o único meio de efetivar essa representação do passado porque é "por meio da elaboração de uma narrativa que se associa à ideia de reconstituição e explicação do vivido" (BARREIROS, 2015, p. 24).

Conforme expresso nas palavras atribuídas a Saussure, "[b]em longe de dizer que o objeto precede o ponto de vista, diríamos que é o ponto de vista que cria o objeto" (SAUSSURE, 2006, p. 15). Partindo desse princípio epistemológico postulado pelo 
linguista genebrino, ressalta-se a necessidade de considerar, no processo de elaboração de narrativas, que os sentidos não residem nos objetos, mas lhes são atribuídos e se encontram condicionados ao pesquisador. A situação se torna ainda mais labiríntica quando se faz necessário atribuir sentidos a objetos provenientes de épocas passadas, já que, segundo Pesavento (2005), o passado não pode ser apreendido em sua totalidade, o que nos impede de construir uma imagem perfeita, um reflexo do decorrido, sendo possível apenas construir algo a partir dele.

Além disso, ao estruturar essas narrativas, deve-se considerar que os objetos do acervo não se constituem isoladamente. Primeiro, pelo fato de que um texto não existe em si mesmo, mas se estabelece a partir de um contínuo diálogo com outros textos. Segundo, por tratar-se, como afirma Barreiros (2016), de uma obra autobiográfica forjada pelo próprio escritor, sua magnum opus, o acervo não pode ser estudado de maneira fragmentada, por meio da análise isolada de cada documento, visto que os documentos compõem uma imensa rede de informações. O rompimento dessas redes é um procedimento arriscado, pois induz o pesquisador a realização de uma leitura limitada, direcionando-o a assumir posicionamentos equivocados com relação ao escritor, ao acervo e, obviamente, ao próprio documento.

O presente trabalho versa sobre a elaboração do dossiê arquivístico, conforme proposto por Barreiros $(2013$; 2015) como parte da metodologia para a realização de edições digitais no projeto Edição das Obras Inéditas de Eulálio Motta. A discussão gira em torno dos dossiês construídos a partir de dois textos: Carta Aberta (28-08-1931), publicada por Eulálio Motta no periódico Mundo Novo ${ }^{1}$, e Carta aberta a um amigo, um rascunho de carta escrito no caderno Farmácia São José2, ambos produzidos com a finalidade de serem publicados em uma hiperedição. Sendo assim, pretende-se contribuir para a construção das narrativas biográficas do escritor, com ênfase em sua trajetória como jornalista e na vida religiosa, além da divulgação das obras presentes em seu acervo, promovendo a literatura e os aspectos linguísticos e culturais preservados nos textos.

\section{POR UMA FILOLOGIA DIGITAL}

Ao se discutir a respeito da origem da filologia, tem-se tradicionalmente remontado aos trabalhos realizados na Biblioteca de Alexandria, no século III a.C., que primavam pelo estabelecimento das obras homéricas, na busca por restituir o sentido inaugural dos textos considerados corrompidos com o passar do tempo. Apesar disso, tem-se constatado que essa preocupação não era uma questão exclusiva dos gregos, mas algo já existente em outras tradições culturais, como a árabe, a hebraica e a hindu (CANO AGUILAR, 2000 apud SANTOS; SOUZA, 2012). Na tradição alexandrina, é possível vislumbrar os primeiros procedimentos metodológicos fundamentais da apuração de textos, como a recensão, a ordenação, o cotejamento de manuscritos, as anotações feitas

\footnotetext{
${ }^{1}$ Plano de trabalho PIBIT/CNPq 2016/2017 desenvolvido por Iago Gusmão Santiago, intitulado Edição digital e constituição do dossiê arquivístico dos textos jornalísticos de Eulálio Motta.

2 Plano de trabalho PIBIC/CNPq/PROCAD 2016/2016 desenvolvido por Stephanne da Cruz Santiago, intitulado Por uma Ação Católica: edição digital e estudo das cartas religiosas do caderno Farmácia São José, de Eulálio Motta.
} 
à margem dos materiais e o uso dos primeiros sinais críticos, antecedentes dos procedimentos críticos e genéticos da atualidade. A partir dessas características, é possível notar que a filologia alexandrina esboçou um modelo de observação do texto pautandose exclusivamente no código alfanumérico, investigando-o com a intenção de expurgar as modificações e, assim, estabelecer um produto limpo, considerado ideal.

No século XIX, nasceu, no âmbito dos estudos filológicos, a Crítica Textual (filologia stricto sensu). Seguindo o legado deixado pela filologia alexandrina, Karl Lachmann (1793-1851), obedecendo o rigor científico da época, propôs um método para a edição crítica de textos bíblicos que objetivava a formação de um arquétipo a partir de um estudo da tradição, possibilitando, dessa forma, o almejado resgate do original perdido. Caracterizado pelo excesso de objetivismo, o método lachmanniano aconselhava a eliminação de qualquer testemunho que pudesse comprometer a pureza do texto (SPINA, 1994). Dessa forma, ancorado nos pressupostos da filologia alexandrina, o método de Lachmann instituiu, de forma mais rígida, uma abordagem que prioriza a superfície linguística do texto. O resultado do empreendimento lachimanniano foi a restituição do texto ausente, um texto que mesmo nunca tendo existido assume o lugar do original perdido.

No século XX, o método de estabelecimento do texto arquetípico de Karl Lachmann passou a ser questionado e intensamente discutido. Nesse período, além das novas propostas feitas com relação ao método estabelecido pelo filólogo alemão, surgiu também a necessidade de adequação a uma nova realidade: a presença do texto autoral. Iniciou-se a busca por resgatar o ânimo autoral em lugar do original perdido, porém dando ainda prioridade ao texto limpo, sem rasuras, emendas ou borrões, favorecendo a elaboração de edições que ignoram os códigos bibliográficos (BARREIROS, 2015, p. 157 158). A Crítica Textual Moderna, apesar de propor um novo caminho a ser trilhado, manteve os mesmos objetivos dos estágios anteriores, baseando-se na visão do texto como construto linguístico, desconsiderando outros aspectos importantes para sua compreensão.

Nota-se, portanto, que, ao longo da sua história, a Crítica Textual firmou seus pilares em uma abordagem desmaterializada do texto, motivada, em parte, pelas crenças em relação ao seu objeto de estudo, que conduziam ao pensamento de que o texto é um produto exclusivamente linguístico, e, em parte, pelas limitações impostas pelas ferramentas ao alcance do filólogo em cada época, que o circunscreviam ao campo das edições impressas. No atual contexto, novas discussões surgiram no âmbito dos estudos filológicos, renovando mais uma vez os conceitos e os métodos empregados. A Crítica Textual passou a ser entendida " [...] como um feixe de práticas de leitura, interpretação e edição que, a um só tempo, consideram como objeto, de modo indissociável, língua, texto e cultura" (SANTOS; SOUZA, 2012, p. 21, grifo dos autores). Seus objetivos passaram a transcender os limites do estabelecimento do código linguístico, buscando resgatar não apenas os sentidos residentes nessa primeira dimensão, mas os significados e as práticas envolvidos na produção, circulação e apropriação dos textos, elementos que se encontram fora dos limites cotextuais.

Dentre as discussões emergentes, encontra-se o questionamento com relação ao estatuto do texto, na busca por apreender as suas partes constituintes. Para Chartier (2001, 
p. 43-44), a realidade textual “[...] não deve ser entendida unicamente em sua dimensão literária, pois também arraiga-se profundamente em sua realidade material [...]". Ou seja, o texto não se restringe apenas a um construto linguístico desmaterializado no qual residem os sentidos, mas apresenta também uma dimensão material que deve ser preservada para que esses não sejam alterados. Ao mudar-se um texto do seu suporte original, a sua realidade é recriada, implicando na geração de novos sentidos. As modificações decorrentes de erros de impressão, a multiplicidade de testemunhos, as notas marginais e outros elementos constitutivos da história do texto fazem parte da sua identidade e necessitam ser considerados pelo filólogo.

Bornstein (2001 apud BARREIROS, 2014, p. 33) apresenta outros elementos necessários para a compreensão efetiva do texto que são os códigos contextuais, os aspectos históricos, sociais e culturais envolvidos na produção, circulação e apropriação desse texto. Spina (1994) também destaca a necessidade desses códigos para tornar o texto inteligível, sendo necessário "[...] interpretá-lo, pontuando-o racionalmente e elucidando as alusões de ordem geográfica, histórica, mitológica, isto é, com o auxílio das disciplinas subsidiárias da Filologia" (SPINA, 1994, p. 87).

Outra questão que tem sido amplamente discutida está relacionada ao que se entende por edição crítica. Conforme aponta Morrás (2003), por meio de um exame superficial de publicações dos últimos anos, é possível notar uma grande insatisfação com o conceito tradicional de edição crítica, concebida como "[...] la producción de un texto singular a partir de una selección de las lecciones de los distintos testimonios o del juicio crítico del editor" "3ORRÁS, 2003, p. 226). Esse descontentamento se dá principalmente pelo fato de haver um nível elevado de subjetividade na elaboração dessas edições, mesmo com as inúmeras tentativas de diminuição da intervenção editorial que se dá pelo uso cada vez mais rigoroso de critérios de edição, e pelo distanciamento das edições críticas, que possuem um caráter idealista, do que se poderia considerar um documento concreto e historicamente real.

Ainda é possível mencionar as dificuldades de leitura impostas pelos aparatos críticos, que, muitas vezes, são apresentados de forma bastante resumida, tornando-se desinteressantes e, em alguns casos, incompreensíveis. A partir desses questionamentos, propõe-se, então, a realização de edições que apresentem a obra ao leitor como um processo e não como um produto, já que a realidade literária se manifesta:

[...] en la serie (no en la suma) de documentos o versiones que han generado las intenciones cambiantes del autor y las sucesivas modificaciones lingüísticas y bibliográficas de la comunidad de recepción (lectores, copistas, impresores), contemplada también como productora de nuevos significados ${ }^{4}$ (MORRÁS, 2003, p. 227).

Ambos os debates teóricos, sobre o que vem a ser o texto e qual seria a forma ideal de editá-lo e apresentá-lo, figuram em um cenário impactado por grandes mudanças

\footnotetext{
3 Tradução nossa: "[...] a produção de um texto singular a partir de uma seleção das lições dos diferentes testemunhos ou do juízo crítico do editor".

${ }^{4}$ Tradução nossa: "[...] na série (não na soma) de documentos ou versões que geraram as intenções mutáveis do autor e as sucessivas modificações linguísticas e bibliográficas da comunidade de recepção (leitores, copistas, impressores), contemplada também como produtora de novos significados".
} 
devido à democratização e ao desenvolvimento acelerado da informática. A filologia, por seu caráter essencialmente interdisciplinar ou pelo fato de ter vislumbrado no ambiente digital a resposta para os questionamentos concernentes ao labor filológico, incorporou com certa naturalidade os novos recursos, vendo neles não apenas uma oportunidade para o aprimoramento da prática editorial, mas uma forma de levar a cabo uma edição capaz de atender às necessidades do seu objeto e de alcançar um maior número de leitores.

É importante considerar as novidades promovidas pelo meio digital no âmbito filológico, mas a tecnologia digital não é por si só a solução para os problemas de edição de textos. No que tange às diversas possibilidades que a cultura digital proporciona, encontra-se a da elaboração de edições que atendam à linguagem da $W e b$, permitam mobilizar as funcionalidades das novas mídias, por meio de interfaces amigáveis, e garantam a interação dos usuários com os documentos editados. No entanto, nota-se que muitas edições elaboradas em meio digital reproduzem as técnicas das edições impressas, mudando apenas o suporte. Esses tipos de edições são considerados por Barreiros (2014) como incunábulos digitais, porque não aproveitam os recursos da tecnologia digital em rede, seguindo apenas os padrões adotados nas edições impressas.

Segundo Patrick Sahle (2017),

Digital scholarly editions are not just scholarly editions in digital media. I distinguish between digital and digitized. A digitized print edition is not a "digital edition" in the strict sense used here. A digital edition can not be printed without a loss of information and/or functionality. The digital edition is guided by a different paradigm. If the paradigm of an edition is limited to the two-dimensional space of the "page" and to typographic means of information representation, than it's not a digital edition ${ }^{5}$.

$\mathrm{Na}$ tentativa de reduzir gastos, os filológicos viram no meio digital a solução para alguns de seus problemas. As edições digitais de obras monumentais demandam o exame de muitos documentos manuscritos que dificilmente cabem numa publicação impressa. Além disso, o custo dessas impressões é muito alto. Entretanto, de um modo geral, não tem havido uma preocupação com a adequação dessas edições ao ambiente digital e, por conta disso, a grande maioria desses projetos resultam em "edições digitalizadas", como diz Shale (2017).

Além da divisão estabelecida por Shale (2017) entre edições digitais e digitalizadas, Lose e Magalhães (2016) classificam o primeiro grupo em dois tipos: edições digitais com não-linearidade dinâmica fechada (NLDF) e não-linearidade dinâmica aberta (NLDA). No primeiro modelo, o editor não utiliza a rede mundial de computadores, mas elabora um arquivo em HyperText Markup Language (HTML), no qual insere links no texto que direcionam o leitor para elementos que integram a própria edição, constituindo-se, portanto, uma edição offline. No segundo, se utiliza a rede mundial de computadores, um

\footnotetext{
${ }^{5}$ Tradução nossa: "As edições filológicas digitais não são apenas edições filológicas em mídias digitais. Eu distingo entre digital e digitalizada. Uma edição impressa digitalizada não é uma 'edição digital' no sentido estrito utilizado aqui. Uma edição digital não pode ser impressa sem uma perda de informação e/ou funcionalidade. A edição digital é guiada por um paradigma diferente. Se o paradigma de uma edição é limitado ao espaço bidimensional da 'página' e aos meios tipográficos de representação da informação, então não é uma edição digital".
} 
modelo online de edição que permite explorar uma vasta quantidade conteúdos externos não produzidos pelo editor.

Ao elaborar-se uma edição com NLDF, algumas questões devem ser observadas. A primeira consiste na escolha dos suportes de armazenamento, tais como CDs, DVDs, pen drives, que não são indicados para o arquivamento de edições devido à sua vulnerabilidade, pois apresentam problemas com exposição a campos magnéticos, oxidação, umidade, poeira. A segunda está relacionada à durabilidade das edições, já que nem os suportes de armazenamento nem alguns softwares garantem o acesso contínuo às edições. É o caso do disquete, por exemplo, que se encontra fora de uso devido à falta de computadores com dispositivos que possibilitem a sua leitura, bem como os novos modelos de portáteis, como notebooks e tablets, que não possuem entradas para CDs e DVDs.

Em contrapartida, segundo Barreiros (2014), essas limitações demonstram que a tendência do futuro é a circulação de publicações via $W e b$. Inúmeras são as vantagens da utilização da rede mundial de computadores. Além das citadas anteriormente, Barreiros (2017a) dá destaque a capacidade de ampla divulgação, constituição de dados e sistemas de buscas, grande capacidade para o armazenamento de informações, dentre outras.

Partindo desses pressupostos, foi proposto por Barreiros (2013; 2015), para as edições digitais do projeto Edição das obras inéditas de Eulálio Motta, um padrão de hiperedição, que, segundo o autor, caracteriza-se por ser

[...] uma hipermídia que geralmente apresenta mais de um tipo de edição convencional crítica, facsimilada, diplomática, sinótica etc., de modo integrado e dinâmico, documentos paratextuais diversos - textos, imagens, vídeos, sons e animações, organizados conforme critérios estabelecidos pelo editor (BARREIROS, 2014, p. 49).

Nessa proposta de edição digital, busca-se aproveitar as potencialidades da informática, utilizando um modelo não-linear, dinâmico e aberto, com o intuito de aproveitar materiais e ferramentas confiáveis que já se encontram disponíveis em rede e podem servir como material complementar, não sendo necessário que todo o material disponível na hiperedição fique a cargo do editor. Nesse caso, os links disponíveis podem levar o leitor/usuário da edição para outros sites e plataformas digitais da $W e b$.

Busca-se, portanto, não apenas uma simples transposição do modelo de edição impressa para o meio digital, mas de uma edição que explore os recursos informáticos para enriquecer a apresentação do texto. A expectativa das edições digitais é que elas criem um ambiente multimidiático que proporcione ao leitor/usuário as oportunidades que se esperam dos ambientes virtuais integrados à $W e b$. Portanto, não pode faltar nas edições digitais (i) a interação por meio de comentários; (ii) o acesso a informações essenciais para a compreensão do texto, com o acesso a links que direcionem tanto para informações internas, preparadas pelo próprio editor, quanto para informações externas, já disponíveis na rede; e (iii) a possibilidade de compartilhar os conteúdos nas redes sociais.

Esse tipo de edição atende ao novo perfil de leitor ubíquo que surge com as mídias digitais em rede e, segundo Santaella (2004), caracteriza-se como uma prontidão cognitiva ímpar para orientar-se entre nós e nexos multimídia, sem perder o controle da sua presença e do seu entorno no espaço físico em que está situado. 
Explorar os recursos da hipermídia permite que se ultrapassem os limites impostos pelo material impresso, sendo possível seguir para além das fronteiras dos documentos editados e do acervo, proporcionando uma leitura expansiva do texto. O editor, então, não publica mais um simples conjunto de caracteres em rede, em lugar disso, compõe um conjunto de arquivos hipermidiáticos conectados por nós.

A realidade textual de cada documento passa a ser representada, considerando as dimensões que a integram: os códigos bibliográficos, com a exibição dos fac-símiles dos documentos e comentários que descrevem aspectos da sua materialidade; os códigos alfanuméricos, com a transcrição do texto de todos os testemunhos, paratextuais e prototextuais. Isso possibilita ao leitor mais interessado a oportunidade de comparar as versões do texto, realizando tanto a leitura linear, quanto hipertextual, acessando os links que direcionam para outros documentos, glossários etc. Os códigos contextuais do texto, elucidando sua sociologia, podem ser explorados por meio de menus específicos para acomodar o dossiê arquivístico, que se configura como uma rede de pontos ligados por afinidades.

As edições digitais podem dispor ainda de sistemas de busca complexos, oferecendo a opção de personalizar o perfil dos usuários para que o site ofereça uma visita ajustada a cada perfil. Segundo Barreiros (2017), as edições digitais precisam dispor de mecanismos para compartilhar e comentar seus conteúdos, ajustando-se ao princípio de interatividade, próprio do ambiente digital, que pode ser observado na linguagem das redes sociais e em outros espaços da $W e b$.

As discussões acerca das edições digitais apresentadas aqui estão baseadas numa realidade textual pautada no acervo do escritor Eulálio Motta. O grupo de pesquisadores vinculados ao projeto Edição das obras literárias de Eulálio Motta lida com documentos integrados a um conjunto - que é o acervo, sendo, portanto, muito difícil editar um desses documentos sem abordá-lo como um sistema complexo e integrado. Eulálio Motta possuía certa compulsão pela leitura e pela escrita, que fazia com que relesse continuamente os textos do seu acervo pessoal e também alterasse por diversas vezes os seus escritos, transformando-os em verdadeiros palimpsestos, que conservaram as marcas deixadas durante esse processo. Por conta disso, os documentos do seu acervo favorecem a elaboração de edições digitais nos modelos descritos acima, já que os documentos estão intimamente integrados como um rizoma que permite a criação de um dossiê arquivístico hipermidiático.

\section{DO MÉTODO ARBORESCENTE AO RIZOMÁTICO}

Um olhar mais aprofundado sobre os princípios idealistas que estão nas bases científicas da Crítica Textual, no final do século XIX, permite observar que tais princípios influenciaram e ainda têm influenciado o modo de construir e ordenar o conhecimento no ocidente. No volume um de Mil Platôs: Capitalismo e Esquirofrenia, Deleuze e Guattari (1995) introduzem uma discussão sobre a maneira ocidental de representação do pensamento, que se encontra, desde a antiguidade clássica, fincada em uma perspectiva arborescente: “[n]o Ocidente a árvore plantou-se nos corpos, ela endureceu e estratificou até os sexos" (DELEUZE e GUATTARI, 1995, p. 29). Utilizando a nomenclatura criada 
pela morfologia vegetal, os autores descrevem modelos de ordenação das ideias, comparando-os a algumas espécies de raízes. O modelo arborescente aparece relacionado à raiz pivotante, uma espécie de raiz que é composta por um pivô, um eixo central mais desenvolvido, de onde partem as raízes secundárias.

O pensamento ocidental, cujo berço é a Grécia antiga, buscou desde os momentos iniciais a ordenação do mundo com a instituição de conceitos e classificações. O sistema arborescente tem a suas origens em Platão, que, utilizando o método dedutivo, aplicado por meio da oposição e da dualidade, buscava direcionar os sujeitos do doxa, do domínio da opinião, ao campo das ideias. Para ele, a filosofia seria "uma busca pela verdade e pelas essências das coisas (as Ideias) que só poderiam ser alcançadas por um discurso e um raciocínio dialético cujo método polarizado priorizava a dualidade no alcance de um conceito Uno" (FERREIRA, 2008, p. 29).

$\mathrm{O}$ padrão de pensamento concebido por Platão corresponde à raiz pivotante que se caracteriza pela aparição explícita do Uno, "[...] uma forte unidade principal, unidade que é suposta para chegar a duas [...]” (DELEUZE e GUATTARI, 1995, p. 13). Segundo os autores, esse tipo de raiz, além de seguir uma lógica binária, desdobrando-se de maneira dicotômica, tal como é possível notar nos procedimentos analíticos da sintaxe gerativa, por exemplo, pode estabelecer também relações biunívocas, porém, nunca abolindo o pivô, de onde provêm as raízes secundárias.

O modelo pivotante pressupõe uma fragmentação do objeto, de modo a criar hierarquias, sendo, em uma escala de importâncias, o tronco mais relevante que os galhos, os frutos e as flores. Dessa forma, na lógica pivotante, há, de modo geral, uma tendência à inferiorização das partes que compõem o objeto, a partir da consideração de que existe uma relação unilateral de dependência (a parte "derivada" é subordinada ao pivô), desconsiderando a possibilidade do pivô também ser dependente da parte dita derivada, em uma relação de reciprocidade e equivalência. O pensamento arbóreo estabelece, portanto, uma linha de raciocínio que impõe um ponto fundamental, estimulando a identificação de subordinações.

$\mathrm{Na}$ Idade Média, a raiz pivotante, por meio da metáfora-chave da árvore e seus galhos, pode ser vista materializada na árvore judiciária, árvore da gramática, árvore dos jesuítas (BURKE, 2003). Segundo o autor, a imagem da árvore, elemento natural, está relacionada ao propósito da naturalização daquilo que é convencionado ou apresentação da cultura como sendo descoberta e não invenção, o que "equivale a negar que os grupos sociais sejam responsáveis pelas classificações, assim sustentando a reprodução cultural e resistindo a tentativas de inovação" (BURKE, 2003, p. 73). Tratava-se, portanto, de uma estratégia para a preservação do poder das classes dominantes e, por conta disso, era utilizada por instituições como a Igreja, por exemplo (Cf. Figura 1).

Posteriormente, a árvore passou a dar lugar à ideia de sistema (BURKE, 2003), que, apesar de muitas vezes não representar explicitamente um formato arborescente, segue a mesma lógica, partindo do pivô para elementos subordinados. Nos nossos dias, as árvores ainda dominam os mais diversos campos das ciências, como a psicanálise, a linguística, com destaque para as teorias estruturalistas, e a informática. O mesmo ocorreu no campo da filologia, desde a elaboração das árvores para representar as relações de parentesco entre as línguas até os métodos tradicionais para o estabelecimento de textos. 


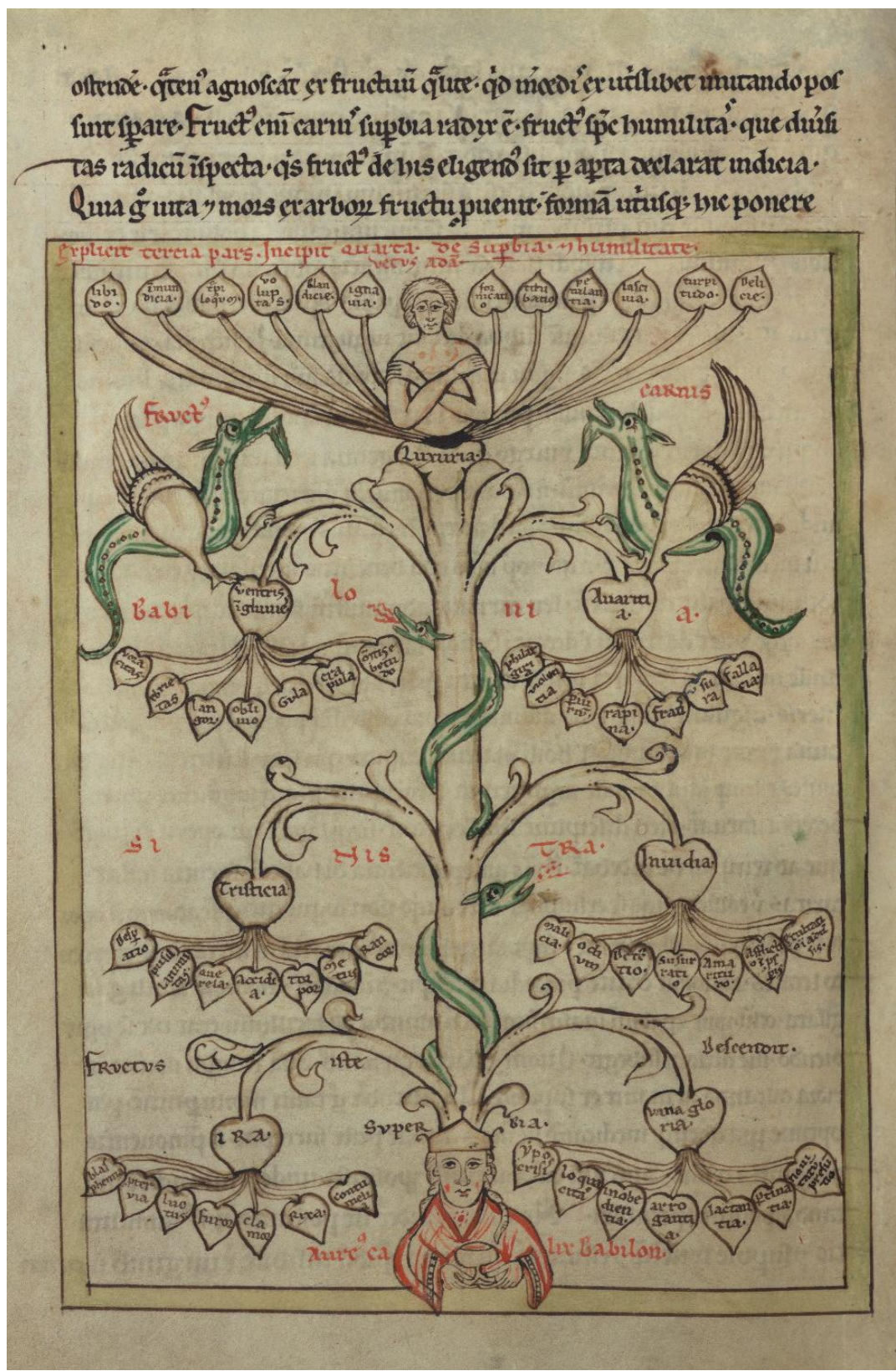

Figura 1: Árvore dos vícios ${ }^{6}$ (exemplo de representação arborescente)

Fonte: Digitized Walters Manuscripts.

${ }^{6}$ Árvore dos vícios (Tree of vices), presente em uma das vinte e duas cópias latinas sobreviventes do Speculum virginum, no fol. $25 \mathrm{v}$, escrito na abadia cisterciense de Himmerode no primeiro quarto do séc. XIII d. C. A imagem foi elaborada com o intuito de apresentar os vícios vinculados aos sete pecados capitais. Nela, podese perceber a existência de um pivô, a figura de Deus com uma taça em mãos, simbolizando a Babilônia (BÍBLIA, Lamentações, 51, 7), de onde partem os ramos que sustentam os sete pecados capitais, ramificando-se, por fim, nos vícios correspondentes. 
Orientados pela visão idealista do texto, os filólogos tradicionais buscaram resgatar o que entendiam por pureza textual: um construto linguístico livre de marcas deixadas pelo tempo, espaço ou pela sociedade em que circulava. Nesse sentido, pode-se constatar que a Crítica Textual nasce e, posteriormente, se consolida como disciplina científica a partir de um enfoque pivotante. Na Crítica Textual Tradicional, esse enfoque se efetivou por meio dos procedimentos postulados pelo alemão Karl Lachmann, que esboçou o método da elaboração de uma árvore genealógica (stemma codicum ou estema), com o intuito de apresentar de modo esquematizado a filiação e a forma que se deu o processo de transmissão dos testemunhos do texto a ser fixado. Desde então, o método arborescente tem acompanhado as mudanças no âmbito dos estudos filológicos, sendo aplicado também por alguns filólogos da chamada Crítica Textual Moderna para a edição crítica de textos autorais. A identificação das campanhas de escrita dos manuscritos, numa abordagem genética, também segue a ideia arborescente, ao tentar ordenar o caos do processo de criação, dando-lhe certa linearidade.

No modelo Lachmanianno de estema (Cf. Figura 2), os testemunhos são representados por letras de acordo com a sua natureza: $\omega$ (ômega) para o arquétipo, letras minúsculas do alfabeto grego para o subarquétipos, maiúsculas latinas para códices membranáceos etc. $\mathrm{O}$ arquétipo, o texto ausente a ser restituído no caso de não existir na tradição um manuscrito autógrafo ou apógrafo, aparece centralizado em um dos extremos da árvore, de onde partem os ramos representantes de cada testemunho que a integra. $\mathrm{O}$ arquétipo assume uma posição privilegiada e os textos ditos "filiados", que servem de fonte para a elaboração desse exemplar ideal, aparecem subordinados a ele. Além disso, os testemunhos considerados inúteis não eram incluídos no estema lachmanniano, resultando num apagamento da sócio-história desse texto. Outras propostas surgiram, trazendo mais flexibilidade e adaptações à proposta de Lachmann, porém seguindo ainda a mesma abordagem idealista e verticalizada.

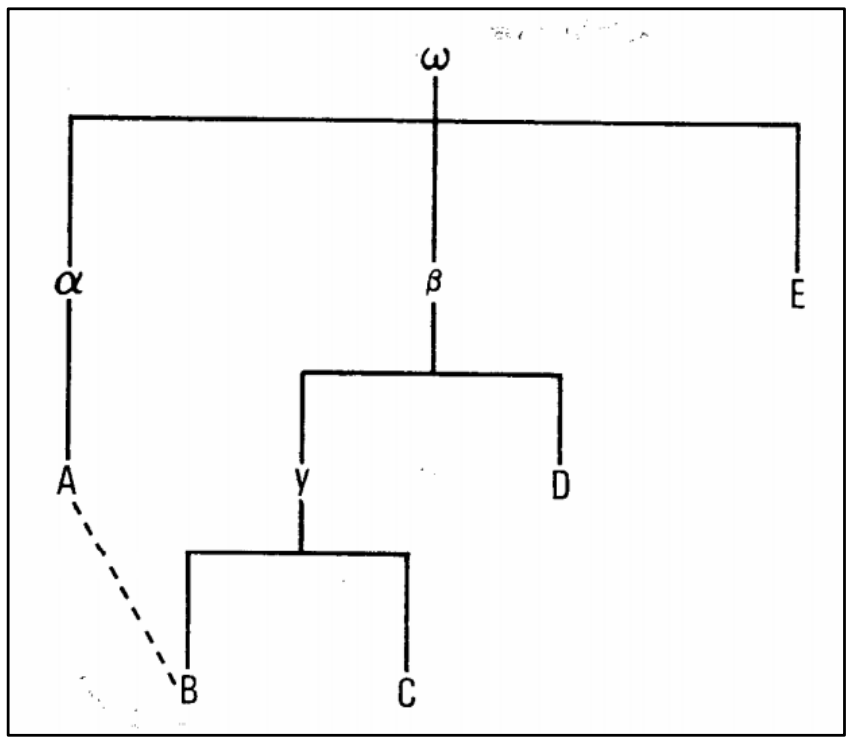

Figura 2: Modelo Lachmanianno de estema

Fonte: Elaborado por Spina (1994, p. 102). 
As novas discussões a respeito do estatuto do texto e da complexidade que o envolve exigem do filólogo um novo olhar sobre o seu objeto de estudo. Por conta disso, nota-se no âmbito da Crítica Textual a busca por uma renovação epistemológica por meio da utilização de novos métodos que sejam também compatíveis com as novas possibilidades proporcionadas pelos recursos digitais. Por outro lado, a apresentação de caminhos alternativos não representa uma invalidação dos métodos tradicionais de estabelecimento do texto, mas a elaboração de um método que permita explorar também outros códigos além do linguístico, considerando o entorno do texto com a intenção de ampliar as suas possibilidades de leitura. As edições críticas podem ser integradas às edições digitais dado o seu caráter sintetizador, possibilitando uma leitura fluida do texto e o acesso direto às suas informações essenciais.

No âmbito das pesquisas em acervos de escritores, novas propostas se mostram ainda mais necessárias para que se possa dar conta das multiplicidades de que são constituídos. O acervo de Eulálio Motta, por exemplo, é composto por manuscritos avulsos, cadernos com textos inéditos, rascunhos de obras publicadas, diários, cartas, postais, fotografias, diplomas, datiloscritos e objetos pessoais. No acervo, podem ser encontrados tanto obras de tradição múltipla a serem cotejadas e editadas criticamente, como um conjunto de borradores que necessitam de edições genéticas. Mas não apenas isso. A pesquisa em acervos oferece inúmeras outras possibilidades a serem exploradas pela Crítica Textual. Por conta disso, faz-se necessário pensar em novas perspectivas de trabalho, que permitam transcender a barreira arborescente e idealista que tem orientado os percursos da filologia ao longo da sua trajetória.

Deleuze e Guattari (1995), na busca por romper com o pensamento arborescente, apresentam um novo modelo epistemológico que desconsidera a unidade e redimensiona o olhar para as multiplicidades. Esse modelo é o rizomático. O termo rizoma é também proveniente da botânica e refere-se a um tipo de caule que cresce de maneira horizontal e possui a capacidade de ramificar-se a partir de qualquer um de seus platôs. Desse modo, o rizoma não apresenta um centro ou um pivô, mas uma variedade de platôs, que podem ramificar-se ilimitadamente e expandir-se em diversas direções, criando conjuntos autônomos. O rizoma é uma nova maneira de interpretar o mundo que busca a representação de sua realidade complexa.

O rizoma nada mais é do que um lugar fronteiriço, já que todas as coisas permanecem em completa conexão. Uma de suas características mais marcantes é a falta de estaticidade, pois o rizoma não "é", mas "está", podendo expandir-se a qualquer momento e criar uma nova conexão. Ele consiste em um modelo que considera a coexistência dialógica das coisas e se estabelece a partir de uma relação conjuntiva. Assim, em linhas gerais, pode-se descrevê-lo da seguinte forma:

Um rizoma não começa nem conclui, ele se encontra sempre no meio, entre as coisas, interser, intermezzo. A árvore é filiação, mas o rizoma é aliança, unicamente aliança. A árvore impõe o verbo "ser", mas o rizoma tem como tecido a conjunção "e... e... e...". Há nesta conjunção força suficiente para sacudir e desenraizar o verbo ser. Entre as coisas não designa uma correlação localizável que vai de uma para outra e reciprocamente, mas uma direção perpendicular, um movimento transversal que as carrega uma e outra, riacho sem início nem 
fim, que rói suas duas margens e adquire velocidade no meio (DELEUZE e GUATTARI, 1995, p. 37).

Segundo Deleuze e Guattari (1995), é possível elencar seis características aproximativas do rizoma: conexão, heterogeneidade, multiplicidade, ruptura asignificante, cartografia e decalcomania. A conexão se dá pela operação ilimitada, visto que "[...] qualquer ponto de um rizoma pode ser conectado a qualquer outro e deve sê-lo. É muito diferente da árvore ou da raiz que fixam um ponto, uma ordem (DELEUZE, GUATTARI, 1995, p. 15). A heterogeneidade encontra-se vinculada à conexão, pois as conexões dentro de um rizoma não se apresentam condicionadas à correspondência tipológica, sendo possível o estabelecimento de conexões entre elementos de âmbito e natureza diversos: "[...] cadeias semióticas de toda natureza são aí conectadas a modos de codificação muito diversos, cadeias biológicas, políticas, econômicas, etc. [...]” (DELEUZE, GUATTARI, 1995, p. 15).

A multiplicidade, conceito de extrema relevância para o pensamento rizomático, já que é o princípio motivador desse modelo, acontece quando não há uma subordinação das partes a uma unidade e o múltiplo se torna substantivo. Para os autores,

Nós não temos unidades de medida, mas somente multiplicidades ou variedades de medida. A noção de unidade aparece unicamente quando se produz numa unidade uma tomada de poder pelo significante ou um processo correspondente de subjetivação: é o caso da unidadepivô que funda um conjunto de relações biunívocas entre elementos ou pontos objetivos [...] (DELEUZE, GUATTARI, 1995, p. 17).

O quarto princípio é o da ruptura a-significante. Do mesmo modo que um rizoma pode estabelecer conexões a partir de qualquer um de seus platôs, ele também pode suportar rupturas que não implicam em um prejuízo com respeito ao significado. Segundo os autores,

Um rizoma pode ser rompido, quebrado em um lugar qualquer, e também retoma segundo uma ou outra de suas linhas e segundo outras linhas. É impossível exterminar as formigas, porque elas formam um rizoma animal do qual a maior parte pode ser destruída sem que ele deixe de se reconstruir (DELEUZE, GUATTARI, 1995, p. 18).

O quinto e o sexto princípios servem como indicações metodológicas para a construção de representações rizomáticas. O princípio da cartografia consiste em uma orientação de como se deve elaborar um rizoma. Para os autores, "[o] mapa é aberto, é conectável em todas as suas dimensões, desmontável, reversível, suscetível de receber modificações constantemente" (DELEUZE e GUATTARI, 1995, p. 22). O rizoma seria, portanto, como um mapa, no sentido de que não reproduz um modelo pré-estabelecido, pois,

Mapear significa acompanhar os movimentos e as retrações, os processos de invenção e de captura que se expandem e se desdobram, desterritorializando-se e reterritorializando -se no momento em que o mapa é projetado. Ao produzi-lo, estamos no plano da invenção e não mais no da representação. Portanto, assim como o rizoma é sempre criador, mapear um acontecimento é um processo de invenção, onde se segue o devir (FERREIRA, 2008, p. 36). 
Já a decalcomania diz respeito ao processo inverso, característico do método arborescente: a reprodução. $\mathrm{O}$ decalque consiste na reprodução de um modelo préexistente. A partir do momento em que a árvore "plantou-se" no ocidente, tem-se reproduzido esse modelo em forma de decalque, aplicando-o a diversas áreas do conhecimento. Ao rizoma, no entanto, não se pode aplicar tal princípio, devido ao seu caráter imprevisível, que impede a criação de um modelo estandarte para a elaboração de rizomas. Esse traço também o diferencia da árvore quanto à questão da naturalização do conhecimento, mencionada por Burke (2003), já que na alegoria do rizoma não se busca utilizar esse aspecto em prol de um ideal reprodutivista.

Considerando esses princípios, pode-se concluir que o objeto da filologia na contemporaneidade é o texto-rizoma, visto a partir de suas múltiplas dimensões. Ao debruçar-se sobre a documentação presente nos acervos de escritores, constata-se que esta não deve ser observada a partir da ótica arborescente, com ênfase na unidade, apenas levando em conta os modelos culturais canonizados e as obras de caráter literário. É necessário refletir sobre a sua verdadeira natureza, a rizomática, manifesta na heterogeneidade de sua constituição e no seu desenho altamente integrado, conforme observa Bordini,

As diversas classes de documentação literária e extraliterária reunidas em um acervo facultam o estabelecimento de relações radiais, entrecruzadas, tais como as que Roland Barthes advogava em $\mathrm{S} / \mathrm{Z}$, entendendo o texto como interação de sistemas significantes sempre em (re)estruturação por força da vitalidade das instituições culturais, ordenados por diversos códigos dinâmicos, artísticos e não-artísticos (BORDINI, 2005, p. 18).

Com base nisso, o padrão de hiperedição apresentado por Barreiros (2013; 2015) busca articular a interface rizomática do ambiente virtual à interface rizomática do texto de acervo. Para tanto, foi desenvolvido um método que possibilita o mapeamento das conexões existentes entre o documento estudado e os demais documentos do acervo, denominado Dossiê Arquivístico. Segundo Barreiros (2015),

O termo dossiê arquivístico designa o conjunto de documentos escolhidos pelo pesquisador do manuscrito para auxiliá-lo na compreensão do texto. Esses dossiês inscrevem-se numa ordem de interesses específicos para o conhecimento de um determinado texto (BARREIROS, 2015, p. 200).

A partir dessa definição, é possível notar que, diferente dos estemas utilizados para a realização de edições críticas, o dossiê arquivístico é um modelo que tem por finalidade estabelecer multiplicidades em detrimento da unidade. Ele se constitui do agrupamento de uma infinidade de pequenas redes de conexão, não sendo apenas composto por um único dossiê, mas um conjunto de dossiês. Cada um desses pequenos grupos é formado a partir do estabelecimento de relações de natureza diversa, que conferem ao resultado final um desenho heterogêneo. O dossiê arquivístico consiste, portanto, em uma proposta rizomática, em que se podem identificar todas as seis características aproximativas do rizoma elencadas por Derleuze e Guattari (1995), conforme mostra a tabela abaixo: 


\begin{tabular}{|c|c|}
\hline $\begin{array}{l}\text { CARACTERÍSTICAS } \\
\text { APROXIMATIVAS } \\
\text { DO RIZOMA }\end{array}$ & APLICAÇÃO AO DOSSIÊ ARQUIVÍSTICO \\
\hline Conexão & São identificadas dentro do acervo linhas de conexão entre os documentos. \\
\hline Heterogeneidade & $\begin{array}{l}\text { As linhas de conexão apresentam naturezas diversas, como temática, } \\
\text { genérica, implícita, explícita. }\end{array}$ \\
\hline Multiplicidade & $\begin{array}{l}\text { O texto não é mais considerado como unidade, mas como multiplicidades, } \\
\text { se materializando no conjunto dos documentos que são percebidos como } \\
\text { extensão deste. Esses documentos complementam, ampliam os sentidos do } \\
\text { texto e, em alguns casos, se mostram indispensáveis para que se possa } \\
\text { compreendê-lo. Não há centralização do texto, visto que qualquer } \\
\text { documento pode tornar-se ponto de partida para a elaboração de um dossiê } \\
\text { e não apenas os textos literários. }\end{array}$ \\
\hline Ruptura a-significante & $\begin{array}{l}\text { Cada dossiê elaborado consiste em um recorte dentro do acervo, havendo } \\
\text { uma ruptura entre o que aparece e o que não aparece na edição. Tal ruptura } \\
\text { não anula a autonomia e a coerência de sentido que são construídas a partir } \\
\text { do dossiê estabelecido. }\end{array}$ \\
\hline Cartografia & $\begin{array}{l}\text { Apesar de haver uma metodologia pensada para a elaboração dos dossiês, } \\
\text { não há uma arquitetura fixa. A estrutura é ditada pelo percurso lógico criado } \\
\text { a partir de cada texto tomado como ponto de partida. }\end{array}$ \\
\hline Decalcomania & $\begin{array}{l}\text { Não se reproduz modelos, cada dossiê se estrutura de uma forma } \\
\text { diferenciada a depender do texto que se toma como ponto de partida. }\end{array}$ \\
\hline
\end{tabular}

Quadro 1: Características do rizoma encontradas no dossiê arquivístico

Fonte: Elaborado pelos pesquisadores com base em Deleuze e Guattari (1995).

O dossiê arquivístico é, dada a sua natureza rizomática, um modelo aberto ao qual se pode agregar um número infinito de relações de natureza diversa. Dentro do acervo do escritor mundonovense, por exemplo, é possível encontrar fotografias, anotações, documentos pessoais, dentre outros objetos, que estabelecem relação com os textos editados. Por conta disso, não é necessário incluir todos os documentos relacionados ao texto estudado na edição, mas apenas os documentos escolhidos pelo editor em função dessa (BARREIROS, 2015).

Um dos argumentos para essa recomendação é o fato de que “[...] não se pode incluir tudo numa edição, além disso, existem certos limites que se impõem à divulgação de documentos de acervos pessoais" (BARREIROS, 2015, p. 200). Todavia, isso não significa que o editor, ao compor um dossiê arquivístico, buscará identificar uma quantidade limitada de relações a partir de interesses específicos, mas, pelo contrário, deve explorá-las ao máximo, visando garantir uma seleção mais rigorosa dos documentos a serem publicados junto à edição, assim como a identificação de redes de conexões que favoreçam outras perspectivas de estudo. No projeto Edições das Obras Inéditas de Eulálio Motta, as edições dos textos têm servido como corpora não somente para a realização de 
estudos literários, sobre a vida e a obra do escritor mundonovense, mas também têm resultado em pesquisas na área de história e em diversos âmbitos da linguística, como a linguística de corpus aliada à lexicologia, lexicografia e sintaxe.

A nomenclatura Dossiê Arquivístico opõe-se a Dossiê Genético porque o primeiro inclui paratextos, prototextos e outros documentos que sinalizam alguma relação com o texto editado, elucidando sua sócio-história, enquanto o segundo inclui apenas os prototextos e os paratextos relacionados ao processo de escrita/criação do texto. No dossiê arquivístico, os documentos são agrupados pelo editor que os interpreta e estabelece a teia de relações, unindo os platôs do rizoma. É importante salientar que o dossiê arquivístico está sempre em expansão, criando novos platôs e estabelecendo novas conexões.

\section{DOSSIÊS ARQUIVÍSTICOS DOS TEXTOS DE EULÁLIO MOTTA}

A elaboração dos dossiês arquivísticos do jornal Mundo Novo e do caderno Farmácia São José foi dividida em duas etapas: (i) dossiê primário e (ii) dossiê secundário. A primeira etapa consiste na identificação das relações de paratextualidade essenciais para a compreensão do texto. Observaram-se as relações que se estabelecem dentro do próprio corpus, nesse caso, as 43 publicações de (e sobre) Eulálio Motta no jornal Mundo Novo e os 40 rascunhos de cartas com o tema religioso escritos no caderno Farmácia São José, além de outros textos que se encontram no mesmo suporte. Consideraram-se também, nesse primeiro momento, algumas relações de caráter explícito, por meio de citações de títulos de obras, trechos de outros textos, como também relações de prototextualidade, entre esses textos, a documentação do acervo e documentos que não constam no acervo mas se encontram disponíveis na internet.

A segunda etapa, a constituição do dossiê secundário, é referente à identificação das relações mais distanciadas ou mais subjetivas entre os documentos do corpus selecionado e os demais documentos do acervo, como é o caso das relações genéricas que conectam o conjunto das cartas, trovas, sonetos etc., ou das temáticas, política, religiosa, amorosa, que são temas recorrentes nos textos do escritor. Enquanto o dossiê primário mostra-se útil para a compreensão do texto editado, o secundário proporciona um mapeamento mais abrangente de como os documentos se relacionam e se organizam dentro do acervo.

A seguir serão apresentados dois exemplos de dossiês: um da Carta Aberta (28-081931), publicada no jornal Mundo Novo, e outro do rascunho de carta intitulado Carta aberta a um amigo, escrito no caderno Farmácia São José. Ambos os textos, além de constituírem rizomas autônomos, apresentam um vinculo genérico, são cartas abertas, que os mantém integrados ao macrocampo rizomático do acervo do escritor. Devido à extensão dos textos, não serão publicados exemplos de edição, mas uma síntese dos seus conteúdos.

\subsection{DOSSIÊ ARQUIVÍSTICO DO TEXTO CARTA ABERTA (28-08-1931)}

A partir da sua primeira edição publicada no dia 12 de setembro de 1920, o jornal Mundo Novo passou a ser o maior veículo de comunicação do município, em que se 
publicavam notícias referentes à cidade de Mundo Novo e região. O jornal permaneceu em circulação até o ano de 1933, quando o seu atual proprietário, Sr. Nemésio Lima, decidiu fechá-lo. Em seguida, ao mudar-se para o município de Jacobina, ele transferiu a tipografia consigo, fundando um novo jornal chamado O Lidador. Segundo Barreiros (2015), esse periódico é um desdobramento do periódico Mundo Novo e por isso manteve certo vínculo com os mundonovenses.

Eulálio Motta iniciou a sua atividade como jornalista no jornal Mundo Novo, publicando textos numa coluna intitulada Rabiscos, entre os anos de 1928 e 1932. Nessa coluna, eram publicados comentários sobre leituras, cartas, de sua autoria e também de autoria de terceiros, crônicas, poemas, que tratavam de temas relacionados ao cotidiano das pequenas vilas, povoados e cidades do sertão baiano e da sua experiência na capital baiana, além de discussões sobre literatura, religião e política. No acervo de Eulálio Motta, encontra-se preservada uma coleção com 49 exemplares de jornais, 44 desses exemplares são cópias de todas as edições do jornal Mundo Novo publicadas entre 24/07/1931 e 24/06/1932 e os únicos testemunhos do jornal de que se tem notícia.

Carta Aberta (28-08-1931) foi publicada no jornal Mundo Novo no dia 28 de agosto de 1931, na página 8, na coluna Rabiscos, entre as colunas 1, 2 e 3. Trata-se de uma correspondência escrita pelo poeta jacobinense Liberato J. M. Barretto para Eulálio Motta, que decidiu publicá-la no periódico na modalidade de carta aberta, como já tinha o costume de fazer com as cartas que julgava importantes ou de interesse coletivo. O texto tem como tema central a crítica ao novo livro de Eulálio Motta, Ilusões que passaram..., lançado nesse mesmo ano. O poeta jacobinense elogia os poemas do escritor, declarando que este tem "o verdadeiro sentimento da poesia", apesar dos seus versos arcaicos, e que ele é um "poeta que escreve poesia" em comparação com outros poetas da época cujas poesias são, para Liberato, verso sem poesia. Além disso, cita trechos dos poemas publicados no livro, bem como o poema Navio Negreiro de Castro Alves, o poeta Casimiro de Abreu e as personagens Romeu e Julieta.

\begin{tabular}{|c|c|c|}
\hline $\begin{array}{c}\text { LOCALIZAÇÃO NO } \\
\text { ACERVO }\end{array}$ & TÍTULO & JUSTIFICATIVA DA INSERÇÃO \\
\hline \multirow{6}{*}{ Jornal Mundo Novo } & Liberato & $\begin{array}{l}\text { Carta aberta publicada por Eulálio Motta } \\
\text { no dia } 23 \text { de outubro de } 1931 \text { em } \\
\text { resposta à carta aberta em questão. }\end{array}$ \\
\hline & Carta aberta (19-02-1932) & $\begin{array}{l}\text { Trata-se também de uma carta aberta } \\
\text { publicada no jornal Mundo Novo. Além } \\
\text { disso, foi escrita por um leitor de Eulálio } \\
\text { Motta comentando um texto publicado } \\
\text { por ele no periódico. }\end{array}$ \\
\hline & "Passaro cègo" & \multirow{4}{*}{$\begin{array}{l}\text { Nesses textos, o escritor também discute } \\
\text { sobre literatura e comenta alguns textos } \\
\text { literários. }\end{array}$} \\
\hline & Aborrecimento & \\
\hline & Dois livros & \\
\hline & Poetas do amor & \\
\hline \multirow{5}{*}{ Livro Ilusões que passaram... } & Ilusões que passara.... & O livro é comentado pelo autor do texto. \\
\hline & COM SAUDADE & \multirow[t]{4}{*}{ São citados trechos do poema. } \\
\hline & VOLTA ILLUS $\tilde{A O}$ & \\
\hline & A DOR MAIOR & \\
\hline & FUTILIDADE & \\
\hline
\end{tabular}




\begin{tabular}{|c|c|c|}
\hline \multirow{4}{*}{ Livro Ilusões que passaram... } & OLHANDO AVIDA & São citados o título e trecho do poema. \\
\hline & DONA FEIA & \multirow[t]{3}{*}{ São citados os títulos dos poemas. } \\
\hline & SOFFRIMENTO & \\
\hline & $O S A B I O$ & \\
\hline Caderno Loja Vitória & Meus amigos: & $\begin{array}{l}\text { No texto, o autor menciona um } \\
\text { comentário feito por Carlos Chiachio } \\
\text { sobre o livro Ilusões que passaram... }\end{array}$ \\
\hline \multirow[t]{2}{*}{ Caderno Luzes do Crepúsculo } & QUANDO EU MORRER... & \multirow{2}{*}{$\begin{array}{l}\text { Prototextos de poemas do livro Ilusões que } \\
\text { passaram... }\end{array}$} \\
\hline & NUNCA MAIS! & \\
\hline \multirow[t]{2}{*}{ Caderno $N^{o} 3$} & Prece de um cético & \multirow{2}{*}{$\begin{array}{l}\text { Prototextos de poema do livro Ilusões que } \\
\text { passaram... }\end{array}$} \\
\hline & Prece de um cetico & \\
\hline
\end{tabular}

Quadro 2: Dossiê arquivístico do texto CARTA ABERTA (28-08-1931)

Fonte: Elaborado pelos pesquisadores.

No dossiê arquivístico, foram inseridos um total de vinte textos. As publicações do jornal Mundo Novo, com exceção de Liberato, que é uma carta aberta em resposta ao texto de em foco, relacionam-se de maneira mais distanciada por meio de uma conexão temática: a discussão literária. Por outro lado, os poemas do livro Ilusões que passaram..., referenciados no texto, os prototextos dos poemas do mesmo livro e o texto Meus amigos:, em que há também uma crítica ao livro de Eulálio Motta, apresentam uma relação direta com o texto de base.

A reunião dos documentos amplia as possibilidades de compreensão do texto de base já que permite o conhecimento integral de textos que são mencionados nele de maneira fragmentada, como é o caso dos poemas do livro Ilusões que passaram..., tema central da publicação, cujo exemplar se encontra no acervo de Eulálio Motta. A carta em resposta revela ao leitor o olhar do escritor com relação ao texto recebido, reconstituindo a sua sócio-história, enquanto que o texto Meus amigos: apresenta outro posicionamento sobre a poesia eulaliana.

\subsection{DOSSIÊ ARQUIVÍSTICO DO TEXTO CARTA ABERTA A UM AMIGO}

O caderno Farmácia São José é composto por 149 folhas (recto e verso), das quais 3 estão em branco. Possui capa dura azul contendo uma colagem de papel personalizada da Farmácia São José, localizada ao centro, com o nome do autor e datada de $1^{\circ}$ de outubro de 1940. Os textos foram escritos em tinta preta e a lápis, contudo, há passagens, geralmente correções, marcações e acréscimos, que se encontram feitas com lápis de cor azul e vermelho; além de um endereço escrito na parte superior da folha $2 \mathrm{v}$., com tinta azul. A encadernação é costurada e suas dimensões são: $166 \mathrm{~mm}$ de largura, $237 \mathrm{~mm}$ de comprimento e $20 \mathrm{~mm}$ de espessura.

A natureza dos textos encontrados no caderno é bastante diversificada. Eulálio Motta fez da maior parte desse caderno um meio de se expressar acerca de vários temas, em forma de cartas, crônicas, anotações do cotidiano, poemas. Há também anotações financeiras, uma peça de teatro, um prefácio de livro que pretendia publicar, além de algumas anotações de leitura. A temática é bastante variada, contendo temas como religião, política, amor, finanças etc. Os textos religiosos, um total de 71 , compõem a maior parte do caderno. 
O texto por título Carta Aberta a um amigo, localizado nas folhas $9 \mathrm{v}-13 \mathrm{v}$, foi escrito no ano de 1941 e faz parte de uma série de cartas encontradas no caderno Farmácia São José, nas quais o escritor discutiu questões religiosas com Eudaldo Lima, entre os anos de 1941 e 1942. Nas cartas, Eulálio Motta tentava convencer Eudaldo de que o catolicismo era a melhor religião, e Eudaldo, por sua vez, tentava provar que o protestantismo era a religião correta a ser seguida, ambos criticando de maneira negativa a religião do outro. A discussão tomou proporções tão grandes que passou do âmbito privado para o público com a publicação de cartas abertas, nas quais os dois amigos compartilhavam suas crenças acerca das religiões e críticas sobre livros religiosos.

De acordo com Eudaldo Lima, em sua carta aberta Declaração Oportuna, publicada no jornal O Lidador, Carta Aberta a um amigo circulou por meio de panfletos avulsos que não se encontram preservados no acervo, sendo o borrador encontrado no caderno Farmácia São José o seu único testemunho de que se tem notícia. A carta publicada por Eulálio faz duras críticas ao livro Cochilos de um sonbador, de Basílio Catalá Castro, um Reverendo da Igreja Presbiteriana, igreja da qual Eudaldo Lima era pastor. O livro em questão foi dado a Eulálio Motta por Eudaldo Lima a fim de discutirem a abordagem religiosa contida nele, porém, com a publicação da carta aberta, Eulálio tornou pública a discussão.

\begin{tabular}{|c|c|c|}
\hline $\begin{array}{l}\text { LOCALIZAÇÃO } \\
\text { NO ACERVO }\end{array}$ & TÍTULO & JUSTIFICATIVA DA INSERÇÃO \\
\hline \multirow{15}{*}{$\begin{array}{l}\text { Caderno Farmácia } \\
\text { São José }\end{array}$} & Meu caro Eudaldo: Saudações & $\begin{array}{l}\text { Carta que precede a carta aberta, em que } \\
\text { Eulálio faz crítica literária do livro } \\
\text { Cochilos de um sonhador e promete a } \\
\text { Eudaldo Lima outros comentários em } \\
\text { carta sequente. }\end{array}$ \\
\hline & $\{2$ de Outubro. Amigo Nemesio. Saudações. $\}$ & $\begin{array}{l}\text { Rascunho cancelado da carta Amigo } \\
\text { Nemésio: Saudaçôs }\end{array}$ \\
\hline & Amigo Nemésio: Saudações & $\begin{array}{l}\text { Carta em que Eulálio questiona } \\
\text { Nemésio Lima sobre o porquê de sua } \\
\text { crônica que critica o livro Cocbilos de um } \\
\text { sonhador, de Basílio Catalá Castro, não } \\
\text { ter sido publicada em O Lidador. }\end{array}$ \\
\hline & Eudaldo amigo: Saudações & \multirow{12}{*}{$\begin{array}{l}\text { As cartas se relacionam por conta do } \\
\text { destinatário em comum. }\end{array}$} \\
\hline & Eudaldo amigo $S /$ *aluto/! & \\
\hline & Eudaldo: /*Saluto!/ & \\
\hline & Eudaldo: $S a\{\uparrow\}$ & \\
\hline & Eudaldo /*amigo/: $\{\dagger\} !$ & \\
\hline & Eudaldo amigo: Salut $\{\uparrow\} !$ & \\
\hline & $E u\{\dagger\} /$ da $\backslash$ do amigo: Respondendo... $[\downarrow I]$ & \\
\hline & $\begin{array}{l}\text { Respondendo II Eudaldo: Ha ou não ha } \\
\text { intermediario? }\end{array}$ & \\
\hline & Respondendo III & \\
\hline & Eudaldo amigo: Salutem! 5-2-942 & \\
\hline & Meu caro: & \\
\hline & Eudaldo: Saudação & \\
\hline
\end{tabular}




\begin{tabular}{|c|c|c|}
\hline & Eudaldo: Saudações & \\
\hline & Eudaldo: Saudações & \\
\hline & Eu\{l\}daldo: Resposta oportuna & \\
\hline & Ponto final & \\
\hline Jornal O Lidador & Declaração Oportuna & $\begin{array}{l}\text { Carta aberta escrita por Eudaldo Lima, } \\
\text { publicada no jornal O Lidador em } \\
\text { resposta à carta aberta escrita por } \\
\text { Eulálio Motta, destinada a Eudaldo, } \\
\text { publicada em avulsos. }\end{array}$ \\
\hline Caderno $N^{0} 3$ & Eudaldo: Pax! & $\begin{array}{l}\text { Destinatário em comum e relação } \\
\text { genérica. }\end{array}$ \\
\hline \multirow{6}{*}{$\begin{array}{l}\text { Não se encontram } \\
\text { no acervo }\end{array}$} & $\begin{array}{l}\text { Livro Cochilos de um sonhador - Basílio } \\
\text { Catalá Castro }\end{array}$ & $\begin{array}{l}\text { Eulálio agradece nesta carta o envio do } \\
\text { livro Cochilos de um sonhador por parte de } \\
\text { Eudaldo Lima. O livro em questão foi } \\
\text { o motivo de diversos debates religiosos } \\
\text { entre Eulálio Motta e Eudaldo Lima, } \\
\text { envolvendo também outras } \\
\text { personalidades da época, como } \\
\text { Nemésio Lima, dono do jornal O } \\
\text { Lidador. }\end{array}$ \\
\hline & $\begin{array}{l}\text { Primeira crônica que Eulálio Motta } \\
\text { escreveu sobre o livro de Basílio Catalá } \\
\text { Castro (Cochilos de um sonhador) }\end{array}$ & $\begin{array}{l}\text { Eulálio cita a crônica na carta Eudaldo } \\
\text { amigo: Saudações, mas não diz se publicou } \\
\text { ou se apenas a enviou para Eudaldo. }\end{array}$ \\
\hline & $\begin{array}{l}\text { Publicação avulsa da carta aberta em } \\
\text { questão }\end{array}$ & $\begin{array}{l}\text { A carta aberta foi publicada em } \\
\text { alvulsos, segundo Eudaldo Lima na } \\
\text { carta Declaração Oportuna. }\end{array}$ \\
\hline & $\begin{array}{l}\text { Livro Dom Quixote de la Mancha - Miguel } \\
\text { de Cervantes }\end{array}$ & $\begin{array}{l}\text { Eulálio cita fragmento do livro de } \\
\text { Basílio Castro em que há citação de } \\
\text { Dom Quixote. }\end{array}$ \\
\hline & $\begin{array}{l}\text { Livro A imitação de Cristo - Tomás de } \\
\text { Kempis }\end{array}$ & $\begin{array}{l}\text { Eulálio Motta diz que mantém este livro } \\
\text { em sua estante e que se trata de é um } \\
\text { dos objetos de sua predileção. }\end{array}$ \\
\hline & Bíblia Sagrada & $\begin{array}{l}\text { Eulálio cita diversos fragmentos da } \\
\text { Bíblia Sagrada na carta aberta. }\end{array}$ \\
\hline
\end{tabular}

Quadro 3: Dossiê arquivístico do texto Carta aberta a um amigo

Fonte: Elaborado pelos pesquisadores.

Por meio do dossiê arquivístico apresentado, é possível compreender o texto Carta Aberta a um amigo e a discussão religiosa entre Eulálio Motta e Eudaldo Lima em uma dimensão muito mais ampla do que se apenas fossem considerados os textos encontrados no caderno Farmácia São José. O dossiê expõe textos citados pelo autor na carta aberta que são importantes para o seu entendimento e de outros textos que o autor escreveu no caderno sob as mesmas circunstâncias.

O dossiê também proporciona o conhecimento de textos importantes que serviram de base para a escrita da carta e, em algum momento, fizeram parte de seu acervo pessoal. Como exemplo disso, pode-se mencionar o livro $A$ imitação de Cristo, de Tomás de Kempis, que, segundo o escritor, ficava em sua estante com outros objetos de sua 
predileção, e o próprio livro Cochilos de um sonhador, de Basílio Catalá Castro, que foi o objeto de discussão da carta aberta.

\section{CONSIDERAÇÕES FINAIS}

Ao editar textos que integram um conjunto documental, como é o caso dos acervos pessoais, o filólogo lida com documentos de natureza diversa e que estão interligados por uma rede de sentidos. Esse é o caso do acervo de Eulálio Motta. O escritor organizou o seu acevo em vida e nota-se que os documentos estão interligados, constituindo-se um rizoma. Retirar um texto do acervo e apresentar a sua edição, sem explorar suas relações como o conjunto documental ao qual ele pertence, seria privar os leitores dos reais significados desse texto.

As edições impressas tradicionais não conseguem dar conta dessa teia de sentidos existente entre o texto e o acervo. Mas, com o advento das tecnologias digitais em rede, abriram-se novas perspectivas para o campo das edições digitais, permitindo que os filólogos explorem novos caminhos metodológicos que estão renovando e ampliando o alcance do labor filológico. Muitos filólogos já utilizam o termo filologia digital para designar a renovação que as tecnologias digitais estão promovendo no campo da edição de textos.

Observa-se que a filologia, em sua essência, continua a mesma. O que está mudando é a forma de abordar o texto, levando em consideração as novas práticas culturais da escrita. A experiência com edições digitais tem demonstrado que é necessário encontrar meios para extrair o máximo que se possa das potencialidades das tecnologias digitais. Nesse sentido, conclui-se que, no ambiente digital, é possível elaborar edições de textos de acervos de modo que se preservem as relações existentes entre os documentos. A elaboração de dossiês arquivísticos pode ser o caminho para explorar o potencial rizomático dos documentos.

A lógica do pensamento rizomático pode ser efetivamente concretizada nas edições de textos, liberando o filólogo da obrigação de estabelecer uma versão única do texto. O meio digital permite explorá-lo sob diversas perspectivas. Os modelos rizomáticos rompem com as hierarquias e decalques dos modelos arborescentes e favorecem as multiplicidades do texto, permitindo apreender o seu devir. Nesse cenário, o dossiê arquivístico se revela uma proposta significativa para a ampliação das discussões no âmbito filológico, pois possibilita a ruptura com a linha arborescente e a revisão do modo de estabelecimento de textos.

Por meio dos dossiês arquivísticos dos textos Carta Aberta (28-08-1931) e Carta aberta a um amigo, é possível perceber como os sentidos são reconstruídos e ampliados à medida que se conhece a documentação citada ou os sujeitos envolvidos na produção desses textos. Além disso, nota-se também a sua relevância para a realização da pesquisa em acervos, já que promove a integração entre documentos diversos e valoriza documentos que seriam pouco explorados em outras abordagens. O editor passa a trabalhar não apenas em função do texto em si, mas do acervo como um todo. 


\section{REFERÊNCIAS}

BARREIROS, Patrício Nunes. Por uma abordagem da História Cultural das práticas de escrita na edição de textos. Alea: Estudos Neolatinos (Impresso), v. 19, p. 389-414, 2017 a.

BARREIROS, Patrício Nunes. Eulálio Motta: um panfletário no sertão da Bahia. Revista do Instituto de Estudos Brasileiros, n. 67, São Paulo, p. 57-80, $2017 \mathrm{~b}$.

BARREIROS, Patrício Nunes. O acervo do escritor e seu itinerário (auto)biográfico. Todas as Letras (Makenzie), São Paulo, v. 18, n. 2, p. 235-250, 2016.

BARREIROS, Patrício Nunes. SANTIAGO, Iago Gusmão. Eulálio Motta: jornalista de Mundo Novo. Anais...VIII Seminário de Estudos Filológicos: Filologia e Humanidades Digitais, Universidade Estadual de Feria de Santana, p. 182-195, 2016.

BARREIROS, Patrício Nunes. SANTIAGO, Stephanne da Cruz. Edição e estudo do caderno Farmácia São José, de Eulálio Motta. Anais...VIII Seminário de Estudos Filológicos: Filologia e Humanidades Digitais, Universidade Estadual de Feria de Santana, p. 92-105, 2016.

BARREIROS, Patrício Nunes. O Pasquineiro da Roça, a biperedição dos panfletos de Eulálio Motta. Feira de Santana: UEFS Editora, 2015.

BARREIROS, Patrício Nunes. Novas práticas culturais da escrita, novas perspectivas da Crítica Textual: rumo às hiperedições. Linguística e Filologia Portuguesa (USP), São Paulo, v. 16, p. 31-62, 2014.

BARREIROS, Patrício Nunes. Da organização do espólio à edição crítica da obra de Eulálio de Miranda Mota. Cadernos do CNLF (CiFEFil), v. IX, p. 117-126, 2005.

BORDINI, Maria da Glória. Acervos de escritores e o descentramento da história da literatura. O Eixo e a Roda, Belo Horizonte, v. 11, p. 15-24, 2005.

BORGES, Rosa; SOUZA, Arivaldo Sacramento de. Filologia e edição de texto. In: BORGES, Rosa; SOUZA, Arivaldo Sacramento de; MATOS, Eduardo Silva Dantas de; ALMEIDA, Isabela Santos de. Edição de Texto e Crítica Filológica. Salvador. Quarteto, 2012. p. $15-59$.

BURKE, Peter. Uma história social do conhecimento: de Gutemberg a Diderot. Rio de Janeiro: Jorge Zahar, 2003.

CHARTIER, Roger. Cultura escrita, literatura e história: Conversas de Roger Chartier com Carlos Aguirre Anaya, Jesús Anaya Rosique, Daniel Goldin e Antônio Saborit. Porto Alegre: Artmed. 2001.

DELEUZE, Gilles; GUATTARI, Felix. Mil platôs - Capitalismo e Esquirofrenia - Volume 1. Tradução de Aurélio Guerra Neto e Celia Pinto Costa. Rio de Janeiro: Editora 34, 1995. 


\section{DIGITIZED WALTERS MANUSCRIPTS. Disponível em:}

<http://www.thedigitalwalters.org/Data/WaltersManuscripts/html/W72/description.h tml>. Acesso em: 15 de maio de 2017.

FERREIRA, Flavia Turino. Rizoma: um método para as redes? Liinc em Revista, v.4, n.1, p.28-40, 2008.

LOSE, Alícia Duhá; MAGALHÃES, Lívia Borges Souza. Reflexões sobre edições digitais: fazendo filologia no século XXI. A Cor das Letras, v. 17, n.1, p. 115-126, 2016.

MORRÁS, María. Informática y crítica textual: realidad y deseos. In: VEGA, María José (Coord.). Literatura bipertextual y teoria literária. La Rioja: Mare Nostrum Comunicación, 2003. p. 225-240.

PESAVENTO, Sandra Jatahy. História e história cultural. 2. ed. Belo Horizonte: Autêntica, 2005.

SANTAELLA, Lucia. Navegar no Ciberespaço. O perfil cognitivo do leitor imersivo. São Paulo: Paulus, 2004.

SAUSSURE, Ferdinand. Curso de Linguística Geral. Cultrix: São Paulo, 2006. SPINA, Segismundo. Introdução à edótica: crítica textual. 2. ed. rev. e atual. São Paulo: Ars Poetica/EDUSP, 1994.

SHALE, Patrick. About, a catalog of: Digital Scholarly Editions, v 3.0, snapshot 2008ff. Disponível em: <http://www.digitale-edition.de/vlet-about.html>. Acesso em: $10 \mathrm{de}$ maio de 2017. 